\title{
Regional localisation of p53-independent apoptosis determines toxicity to 5-fluorouracil and pyrrolidinedithiocarbamate in the murine gut
}

\begin{abstract}
SP Bach ${ }^{*, 1,2}$, SE Williamson ${ }^{2}$, ST O'Dwyer ${ }^{3}$, CS Potten $^{4}$ and AJM Watson ${ }^{5}$
'Nuffield Department of Surgery, University of Oxford, Level 2, John Raddliffe Hospital, Oxford OX3 9DU, UK; ${ }^{2}$ Paterson Institute, Wilmslow Road, Manchester M20 4BX, UK; ${ }^{3}$ Department of Surgery, Christie Hospital National Health Service Trust, Wilmslow Road, Manchester M20 4BX, UK; ${ }^{4}$ Epistem, The Incubator Building, 48 Grafton Street, Manchester MI 3 9XX, UK; ${ }^{5}$ Gastroenterology Research Group, The Henry Wellcome Laboratory, Nuffield Building, University of Liverpool, Crown St, Liverpool L69 3BX, UK
\end{abstract}

\begin{abstract}
Pyrrolidinedithiocarbamate (PDTC) enhanced the activity of 5-fluorouracil (5-FU) in a colorectal cancer xenograft model. Pyrrolidinedithiocarbamate also reduced gastrointestinal toxicity associated with 5-FU therapy in large but not small bowel. We sought to clarify the basis of this differential enteric toxicity. Apoptosis and mitosis were assessed on a cell positional basis in small and large intestinal crypts of $p 53$ wild-type $(+/+)$ and $p 53$ null $(-/-)$ mice $6,12,24,36,48$ and $72 \mathrm{~h}$ after the administration of high $\left(200 \mathrm{mg} \mathrm{kg}^{-1}\right)$ or low $\left(40 \mathrm{mg} \mathrm{kg}^{-1}\right)$ dose $5-\mathrm{FU} \pm 250 \mathrm{mg} \mathrm{kg}^{-1}$ PDTC. Regimens were chosen to model a single human dose and a weekly schedule. The effects of another antioxidant N-acetylcysteine (NAC) were also investigated. Large intestinal crypts affect apoptosis purely by p53-dependent mechanisms, whereas small intestinal crypts are able to initiate both p53-dependent and -independent pathways following treatment with 5-FU. Pyrrolidinedithiocarbamate and NAC antagonised p53-dependent but potentiated p53-independent apoptotic activity. Consequently, the proportion of surviving clonogens increased in the large but not in the small intestine. Regional availability of p53-dependent and -independent apoptotic pathways in small and large intestine together with separate modulation of these pathways by antioxidants explains the different regional enterotoxicity following 5-FU therapy. British Journal of Cancer (2006) 95, 35-4I. doi: I0.1038/sj.bjc.6603224 www.bjcancer.com
\end{abstract}

(c) 2006 Cancer Research UK

Keywords: colorectal cancer; 5-fluorouracil; pyrrolidinedithiocarbamate; N-acetylcysteine; p53; apoptosis

The dose-limiting enteric side effects of 5-fluorouracil (FU) are due to a profuse wave of $\mathrm{p} 53$-driven apoptosis within normal intestinal crypts accompanied by prolonged cell cycle arrest (Pritchard et al, 1998). The antioxidants pyrrolidinedithiocarbamate (PDTC) and $\mathrm{N}$-acetylcysteine (NAC) have been shown to enhance the activity of 5-FU against colorectal cancer cell lines independent of p53 function (Chinery et al, 1997; Bach et al, 2001). This is important as p53 is frequently mutated in human cancer (Levine et al, 1991). Although PDTC increased 5-FU-induced apoptosis within tumour xenografts through the induction of $\mathrm{p} 21^{\mathrm{WAF} 1 / \mathrm{CIP} 1}$ via CCAAT/ enhanced binding protein $\beta$ (Chinery et al, 1997), gastrointestinal toxicity was unexpectedly reduced (Bach et al, 2000). Pyrrolidinedithiocarbamate significantly improved colonic clonogen survival following the administration of 5-FU, whereas small intestinal toxicity remained unchanged. This may be of biological significance as 5-FU was a factor of $1 \log$ more toxic to large, compared to small intestinal crypts. Similar relative toxicities have previously been reported in humans (Milles et al, 1962). Reduced apoptosis among colonic clonogens and prompt restoration of normal

\footnotetext{
*Correspondence: Dr S Bach, Department of Colorectal Surgery, Univeristy of Oxford, Level 2, John Radcliffe Hospital, Oxford 0X3 9DU, UK; E-mail: simon.bach@nds.ox.ac.uk

Revised 3 May 2006; accepted 17 May 2006
}

mitotic activity appeared to account for the reduction in druginduced toxicity. Separate investigators have independently demonstrated the ability of antioxidant compounds to ameliorate the toxicity of 5-FU and a range of other chemotherapeutic compounds, including oxaliplatin and paclitaxel (Alexandre et al, 2006b).

Reactive oxygen species (ROS) are unstable molecules derived from normal mitochondrial metabolism. They set about obtaining additional electrons from other molecules, such as DNA, proteins and cell membranes. As a result of these interactions, donors may incur structural damage that has led to the classical conception of ROS as toxic metabolites. Antioxidants such as PDTC are electron donors that have cytoprotective properties in disease states that induce oxidative stress such as liver cirrhosis (Bruck et al, 2002) and transplant reperfusion injury (Ross et al, 2000; Tsuchihashi et al, 2003).

Good evidence now suggests that ROS also act as physiological signalling molecules in a number of cellular processes including proliferation and apoptosis. In this context, antioxidants such as NAC exert an antiproliferative effect (Sekharam et al, 1998; Nargi et al, 1999; Menon et al, 2003; Kang et al, 2004). This is of special interest given that ROS production may be essential for the growth of p53-deficient colorectal tumours (Sablina et al, 2005).

A third emerging view of antioxidants is as cellular markers for apoptosis or necrosis following cytotoxic drug treatment. 
Generation of $\mathrm{H}_{2} \mathrm{O}_{2}$ was consistently detected following treatment with camptothecin, vinblastine, inostamycin and adriamycin in a lung tumour cell line (Simizu et al, 1998). Scavenging of $\mathrm{H}_{2} \mathrm{O}_{2}$ caused failure of apoptosis. Reactive oxygen species generation has been demonstrated in a range of tumours $6-48 \mathrm{~h}$ after treatment with various anticancer agents (Ikeda et al, 1999; Huang et al, 2003; Fawcett et al, 2005; Rahmani et al, 2005). Indeed, the antitumour activity of paclitaxel in mice was abolished by NAC as accumulation of $\mathrm{H}_{2} \mathrm{O}_{2}$ is an early and crucial step for paclitaxel-induced cancer cell death (Alexandre et al, 2006a).

In this study, we sought to clarify the basis of differential small and large bowel toxicity following combined treatment with PDTC and 5-FU. We determined the availability of p53-dependent and -independent apoptotic pathways in the small and large intestine following 5-FU therapy and characterised the effect of PDTC upon each pathway. We hypothesised that 5-FU would initiate activity in both types of pathway but that separate modulation by PDTC at this level might account for the differences in small and large intestinal clonogenic stem cell survival. We measured p53-dependent and -independent apoptosis in the small and large intestine of p53 wild-type and knockout mice 6, 12, 24, 36, 48 and $72 \mathrm{~h}$ after high- or low-dose 5-FU therapy administered with or without PDTC. We also determined the effects of a separate antioxidant, NAC, upon 5-FU-induced apoptosis in the small and large intestine.

\section{MATERIALS AND METHODS}

\section{Animals}

p53 wild-type $(+/+)$ and p53 null $(-I-)$ mice were from a colony housed at the Paterson Institute for Cancer Research, Manchester, UK derived from those generated by Donehower et al (1992). Mice were aged 10-12 weeks, weighed approximately $25 \mathrm{~g}$ and were kept under a $12 \mathrm{~h}$ light, $12 \mathrm{~h}$ dark regimen, with free access to water and the RM1-expanded diet (Special Diet Services, Waltham, Essex, UK). Experiments were performed in accordance with the Animals (Scientific Procedures) Act 1986 and revised UKCCCR guidelines (1997).

\section{Materials}

5-Fluorouracil (Roche, Welwyn Garden City, UK) was administered at $5 \mathrm{mg} \mathrm{ml}^{-1}$ or $25 \mathrm{mg} \mathrm{ml}^{-1}$ depending upon dose. Pyrrolidinedithiocarbamate (Sigma, Poole, UK) and NAC (Sigma, Poole, UK) were freshly prepared in $0.9 \%$ (wt/vol) saline to a concentration of $6.25 \mathrm{mg} / 0.2 \mathrm{ml}$. Drug administration was by bolus intraperitoneal injection with the first injection given at 0900 hours. Pyrrolidinedithiocarbamate or NAC were administered $15 \mathrm{~min}$ before 5-FU. Optimum times for apoptotic assessment were determined from previous studies (Pritchard et al, 1997; Pritchard et al, 1998; Bach et al, 2000).

\section{Effects of treatment upon apoptosis and mitosis in the small and large intestine}

Apoptosis and mitosis were assessed on a cell positional basis in small and large intestinal crypts of p53 wild-type $(+/+)$ and p53 null $(-/-)$ mice $6,12,24,36,48$ and $72 \mathrm{~h}$ after administration of (a) low-dose 5-FU ( $\left.40 \mathrm{mg} \mathrm{kg}^{-1}\right) \pm 250 \mathrm{mg} \mathrm{kg}^{-1}$ PDTC and (b) high-dose 5-FU $\left(200 \mathrm{mg} \mathrm{kg}^{-1}\right) \pm 250 \mathrm{mg} \mathrm{kg}^{-1}$ PDTC. The effects of another antioxidant NAC were determined in wild-type and null mice 24 and $48 \mathrm{~h}$ after administration of high-dose 5-FU $\left(200 \mathrm{mg} \mathrm{kg}^{-1}\right) \pm 200 \mathrm{mg} \mathrm{kg}^{-1} \mathrm{NAC}$.

The rationale for choosing $40 \mathrm{mg} \mathrm{kg}^{-1} 5$-FU is that it models a single human dose (Pritchard et al, 1997). The $\mathrm{LD}_{50}$ for $5-\mathrm{FU}$ in the mouse is reported to be in the order of $450 \mathrm{mg} \mathrm{kg}^{-1}$ (Burns and Beland, 1984). We have corroborated this figure for the p53 knockout mouse (Bach, 2003). The higher dose of $200 \mathrm{mg} \mathrm{kg}^{-1}$ 5 -FU is equivalent to $600 \mathrm{mg} \mathrm{m}^{-2}$ in this mouse, the exact concentration of 5-FU employed for weekly combination schedules with folinic acid in humans (Buroker et al, 1994). PDTC $\left(250 \mathrm{mg} \mathrm{kg}^{-1}\right)$ was the maximum tolerated as a single dose in previous experiments utilising the BDF1 mouse (Bach et al, 2000), whereas $200 \mathrm{mg} \mathrm{kg}^{-1}$ NAC approximates to the clinical dose used in humans (Prescott et al, 1989).

Mice were culled by cervical dislocation and intestinal specimens promptly harvested. Six mice were utilised per experimental group at each time point. Control animals, injected with saline $(0.2 \mathrm{ml})$, were culled at the first time point. Small and large intestine were prepared by methods described in detail previously (Merritt et al, 1996). Apoptotic bodies and mitotic figures were easily identified in haematoxylin- and eosin-stained sections by their characteristic morphological appearance. We validated morphological scoring of apoptosis against the terminal deoxynucleotide transferase labelling (TUNEL) technique (ApopTag; Oncor, Gaithersburg, MD, USA) (Bach, et al 2000). Statistically valid results can be obtained by examining 200-300 half-crypt sections from 4-6 mice, per group (Chwalinski and Potten, 1989). Good cross-sections cut through the centre of a crypt's longitudinal axis were examined using light microscopy (magnification $\times 640$ ). Each crypt was considered as two-halves, divided along the luminal axis with cells numbered sequentially from the crypt base. Each position was scored as containing a normal cell, an apoptotic cell (with one or more apoptotic bodies) or a mitotic figure. Data were recorded using a PC microcomputer and software developed at the Paterson Institute (Ijiri and Potten, 1983). Group treatment was masked and a single observer (SPB) scored the slide sections. For each cell position, apoptotic and mitotic indices were calculated as percentages. Data may be pooled over a series of adjacent cell positions enabling comparisons to be made between stem, presumed clonogenic and transitional cell zones within the crypt. Results were analysed by a computer program developed at the Paterson Institute based on the median test, a nonparametric ranking test (Potten et al, 1990). P-values less than 0.001 were considered significant.

\section{Detection of $\mathrm{p} 21^{\mathrm{WAF} 1 / \mathrm{CIP} 1}$}

Intestinal samples were stained for $\mathrm{p} 21^{\mathrm{WAF} 1 / \mathrm{CIP} 1}$; ab5 (Oncogene, San Diego, CA, USA). Positive controls: irradiated mouse enterocytes demonstrate nuclear staining. Negative controls: substitution of nonimmune serum for primary antibody on a second tissue section. Antigen retrieval was achieved by microwaving at high power $(800 \mathrm{~W})$ for $20 \mathrm{~min}$. Primary antibody concentrations of $1: 200$ were determined by serial dilutions. Samples were processed using the avidin-biotin complex immunoperoxidase staining system (Santa Cruz Biotechnology, Santa Cruz, CA, USA), developed with diaminobenzidine and counterstained with thionine blue.

\section{RESULTS}

A five-fold increase in the dose of 5-FU administered from 40 to $200 \mathrm{mg} \mathrm{kg}^{-1}$ did not dramatically affect either the kinetics of onset of apoptosis, the magnitude of the apoptotic response or the cell positional incidence of apoptosis within small or large intestinal crypts of wild-type animals. Dose escalation did considerably extend the period of mitotic suppression. We shall describe results obtained with $200 \mathrm{mg} \mathrm{kg}^{-1}$ in detail (data obtained following administration of $40 \mathrm{mg} \mathrm{kg}^{-1} 5$-FU can be found in supplementary files). Administration of PDTC as a single agent had no effect upon apoptotic or mitotic indices (data not shown). 


\section{Colon}

Wild type 5-Fluorouracil increased apoptosis in p53 wild-type large intestinal crypts with maximal values at $24 \mathrm{~h}$ in the presumed clonogenic stem cell compartment (cell positions 4-9) (Figure 1A and $\mathrm{B}$ ). Normal values were restored by $36 \mathrm{~h}$. Following coadministration of PDTC, significantly less apoptosis occurred at $24 \mathrm{~h}$ (Figure $1 \mathrm{~A}$ and $\mathrm{B}$ ). Clonogenic and transit cells were reprieved (cell positions $6-13, P<0.001) . \quad N$-acetylcysteine also inhibited apoptosis at $24 \mathrm{~h}$ (Table 1 ).

Administration of 5-FU produced a prompt decrease in the mitotic index at $6 \mathrm{~h}$ with a complete cessation of almost all measured activity by $24 \mathrm{~h}$ (Figures 2A). Recovery remained incomplete at $72 \mathrm{~h}$. Coadministration of PDTC facilitated early restoration of normal mitotic activity among clonogenic stem cells at $72 \mathrm{~h}$ (cell positions $4-9, P<0.001$ ) (Figure 2B).

Null No significant elevation in apoptotic values occurred within p53 null colonic crypts throughout the entire 72-h period following $5-F U \pm$ PDTC (Figure 1A) or NAC (Table 1). 5-Fluorouracil decreased the mitotic index at $6 \mathrm{~h}$ with only partial recovery by $72 \mathrm{~h}$ (data not shown). The addition of PDTC did not significantly alter these parameters.

\section{Small intestine}

Wild type 5-Fluorouracil alone increased apoptosis in p53 wildtype small intestinal crypts with maximal values occurring between 12 and $24 \mathrm{~h}$ within the clonogenic stem cell compartment (Figure $3 \mathrm{~A}$ and Supplementary data). The addition of PDTC delayed the onset of apoptosis from 6 to $12 \mathrm{~h}$ across all compartments with peak values seen later between 24 and $36 \mathrm{~h}$ (Figure $3 \mathrm{~A}$ ). $\mathrm{N}$-acetylcysteine increased apoptosis at $48 \mathrm{~h}$ (Table 1 ).

5 -Fluorouracil produced a prompt decrease in the mitotic index at $6 \mathrm{~h}$ with recovery at $72 \mathrm{~h}$ (data not shown). Coadministration of PDTC did not modulate these parameters (data not shown).

Null 5-Fluorouracil alone produced a modest elevation in apoptosis above baseline values at the $12,24,36$ and $48 \mathrm{~h}$ time points (Figure $3 \mathrm{~A}$ ). The addition of PDTC delayed the onset of apoptosis beyond $12 \mathrm{~h}$ (Figure $3 \mathrm{~A}$ ), and by $48 \mathrm{~h}$, peak values were double than those observed with 5-FU alone throughout the whole crypt axis (cell positions $3-18, P<0.001$ ) (Figure 3B). Similarly, elevated peak values were seen following NAC (Table 1). Peak values equated to those measured in similarly treated wild-type animals. This late rise in apoptosis within p53 null small intestinal crypts was also seen following $40 \mathrm{mg} \mathrm{kg}^{-1} 5-\mathrm{FU}+\mathrm{PDTC}$ at $36 \mathrm{~h}$; cell positions 3-13 $(P<0.001)$ (Supplementary data).

5 -Fluorouracil produced a prompt decrease in the mitotic index at $6 \mathrm{~h}$ with complete cessation of almost all measured activity up to $72 \mathrm{~h}$ at which point recovery occurred (data not shown). Coadministration of PDTC did not modulate these parameters (data not shown).

\section{p21 ${ }^{\mathrm{WAF} 1 / \mathrm{CIP} 1}$ expression in small intestinal crypts}

No $\mathrm{p} 21^{\mathrm{WAF} 1 / \mathrm{CIP} 1}$ expression occurred in controls (saline injection) (data not shown). Elevated nuclear expression of the p 21 WAF1/CIP1 protein occurred within the transit cell population $6 \mathrm{~h}$ after administration of PDTC $\pm 5-\mathrm{FU}$ (data not shown) with maximal staining intensity in surviving cells at $48 \mathrm{~h}$ (Figure $4 \mathrm{~A}$ ), resolving by $72 \mathrm{~h}$. Nuclear staining was determined on a cell positional basis at $48 \mathrm{~h}$ with high labelling indices among animals treated with $5-F U \pm$ PDTC concentrated about cell positions $6-10$ and no statistically significant difference between groups (data not shown).
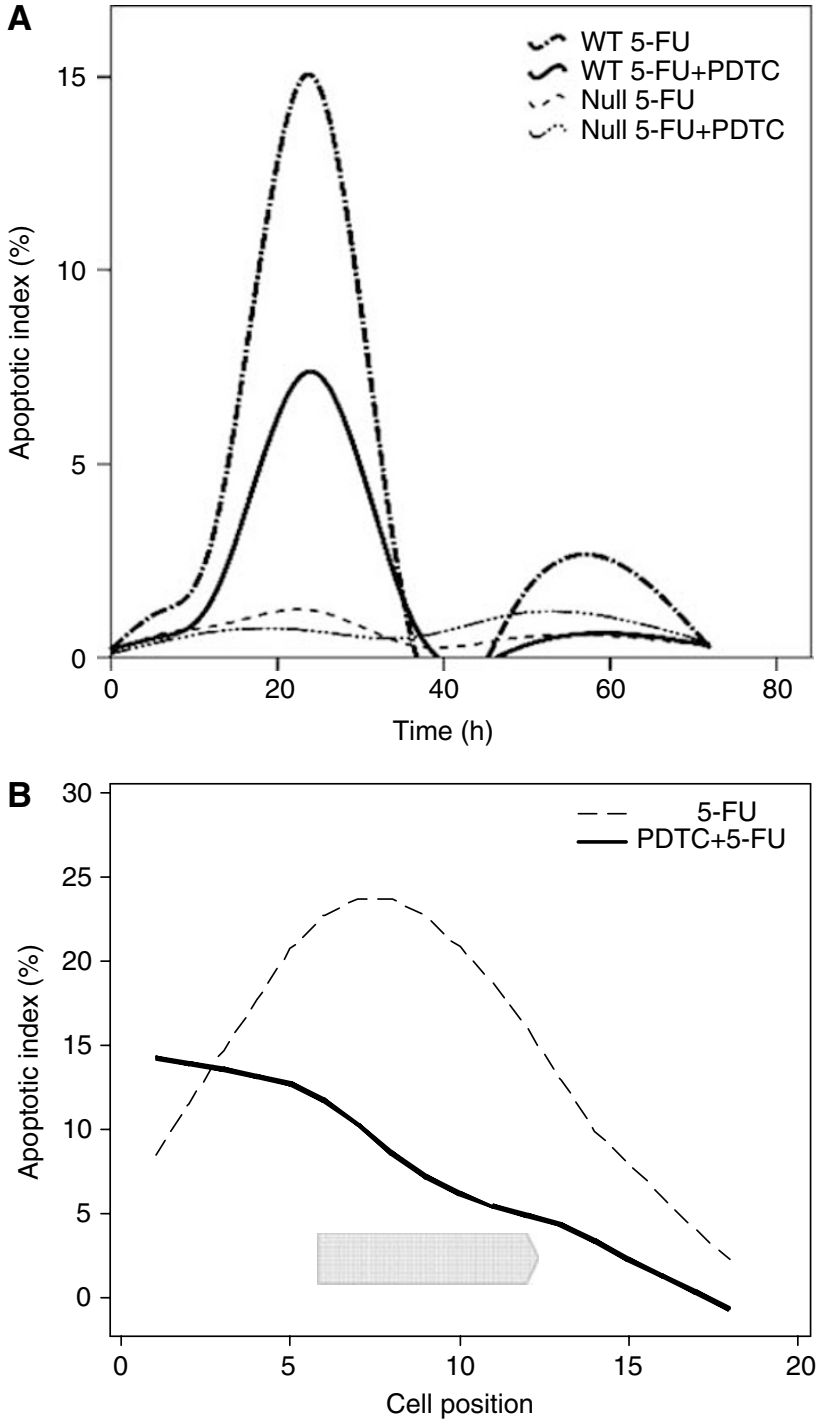

Figure I Large intestinal apoptosis. (A) Time course of mean apoptotic index is displayed for the whole crypt (cell positions I-18) following $200 \mathrm{mg} \mathrm{kg}^{-1} 5$-FU alone $\pm 250 \mathrm{mg} \mathrm{kg}^{-1}$ PDTC in p53 wild-type and p53 null mice. Six animals per group at each time point $(6,12,24,36,48$ and $72 \mathrm{~h}$ ) counting 50 half-crypts per mouse. (B) Apoptotic index is displayed for each crypt cell position $24 \mathrm{~h}$ after the administration of treatment in p53 wild-type mice. Chevron indicates cell positions over which a significant difference was detected between treatments $(P<0.00$ I, PC crypts).

Despite achieving high levels of apoptosis within small intestinal crypts of p53 null mice treated with PDTC/5-FU, no significant induction of $\mathrm{p} 21^{\mathrm{WAF} 1 / \mathrm{CIP} 1}$ occurred at any time point (Figure $4 \mathrm{~B}$ ).

\section{DISCUSSION}

\section{Large intestinal toxicity}

In p53 wild-type large intestine, administration of 5-FU alone produced an isolated apoptotic peak in all crypt compartments at $24 \mathrm{~h}$ (Figure 1A). Coadministration of PDTC and NAC significantly reduced the number of apoptotic events measured at $24 \mathrm{~h}$, especially among clonogenic stem cells (Figure 1B). Apoptotic activity in p53 null colon remained at baseline values throughout the $72 \mathrm{~h}$ period regardless of whether PDTC or NAC were also administered (Figure 1A). Pyrrolidinedithiocarbamate facilitated early mitotic 
Table I Large and small intestinal apoptotic activity in p53 wild-type and p53 null mice following high dose 5 -FU $\left(200 \mathrm{mg} \mathrm{kg}^{-1}\right) \pm N A C$ $\left(200 \mathrm{mg} \mathrm{kg}^{-1}\right)$

\begin{tabular}{|c|c|c|c|c|c|}
\hline \multirow[b]{3}{*}{ p53 } & \multirow[b]{3}{*}{ Time (h) } & \multicolumn{4}{|c|}{ Apoptotic index (\%) } \\
\hline & & \multicolumn{2}{|c|}{ Large intestine } & \multicolumn{2}{|c|}{ Small intestine } \\
\hline & & 5-FU & 5-FU+NAC & 5-FU & 5-FU+NAC \\
\hline \multirow[t]{3}{*}{ Wild-type } & Control & 0.21 & 0.21 & 0.22 & 0.22 \\
\hline & & 15.05 & $6.40^{\mathrm{a}}$ & 7.80 & 8.21 \\
\hline & 48 & 1.10 & 0.33 & 4.39 & $6.20^{\mathrm{a}}$ \\
\hline \multirow[t]{3}{*}{ Null } & Control & 0.09 & 0.09 & 0.18 & 0.18 \\
\hline & 24 & 1.11 & 0.72 & 5.12 & 6.68 \\
\hline & 48 & 0.48 & 0.42 & 5.39 & $10.93^{\mathrm{a}}$ \\
\hline
\end{tabular}

Apoptotic indices are expressed for the crypt as a whole over cell positions $|-| 8$. Six animals were used in each group, counting 50 half-crypts per mouse. Control values (saline injection) are shown in 'normal typeface' as are treatment indices that do not significantly differ from these baseline values $(P>0.001$, $P C$ crypts). Treatment indices outside control values are displayed in bold $\left(P<0.001, P C\right.$ crypts). ${ }^{a} \mathrm{~A}$ significant difference between 5-FU and 5-FU/NAC treatments at a specific time point $(P<0.00$ I, PC crypts).

recovery in the wild-type colon at $72 \mathrm{~h}$ (Figure 2B), whereas recovery at this time point remained incomplete in mice treated with 5-FU alone (Figure 2B). In summary, the murine large intestine initiated only p53-driven apoptosis in response to 5-FU. These events were inhibited by both PDTC and NAC producing a marked improvement in the proportion of surviving clonogens. Mitotic recovery was subsequently enhanced and tissue regeneration as measured by the crypt survival assay improved (Bach et al, 2000).

\section{Small intestinal toxicity}

In p53 wild-type small intestine, 5-FU initiated a rise in apoptosis within $6 \mathrm{~h}$; peak values occurred between 12 and $24 \mathrm{~h}$ (Figure $3 \mathrm{~A}$ ). Pyrrolidinedithiocarbamate did not simply antagonise maximal apoptotic values as occurred in the large intestine. At 6 and $12 \mathrm{~h}$, PDTC reduced apoptosis among stem, presumed clonogenic and transit cell populations (Figure 3A and Supplementary data). The situation was subsequently reversed as PDTC then led to higher apoptotic values compared to 5-FU alone at 24 and $36 \mathrm{~h}$ (Figure 3A). Higher apoptotic values were observed at $48 \mathrm{~h}$ following administration of 5-FU and NAC (Table 1). No difference in mitotic recovery was seen in the wild-type small intestine following PDTC. A combination of reduced clonogen availability and prolonged $\mathrm{p} 21^{\mathrm{WAF} 1 / \mathrm{CIP} 1}$ expression will limit mitotic recovery under these circumstances (Pritchard et al, 1998).

In contrast to results from p53 null large bowel, increased apoptotic activity was recorded in the p53 null small intestine following 5-FU administration. It was also notable that dose escalation from 40 to $200 \mathrm{mg} \mathrm{kg}^{-1} 5$-FU produced a markedly increased the magnitude and duration of apoptotic activity (Supplementary data). At $200 \mathrm{mg} \mathrm{kg}^{-1}$ 5-FU, peak apoptotic values in the p53 null small intestine approached those seen in wild types, although these values occurred somewhat later in null littermates, between 24 and $48 \mathrm{~h}$ (Figure 3A). Pyrrolidinedithiocarbamate and NAC significantly augmented peak levels of p53independent apoptosis at 36 and $48 \mathrm{~h}$ by a factor of two to three (Figure $3 \mathrm{~A}$ and $\mathrm{B}$ and Table 1). Despite finding abundant $\mathrm{p} 21^{\mathrm{WAF} 1 /}$ CIP1 expression within wild-type small intestinal crypts at these time points (Figure 4A), no expression was detected within p53 null enterocytes (Figure 4B). This is in contrast to a previous report utilising PDTC and 5-FU therapy in p53 null colorectal cancer cell lines where PDTC was found to induce apoptosis
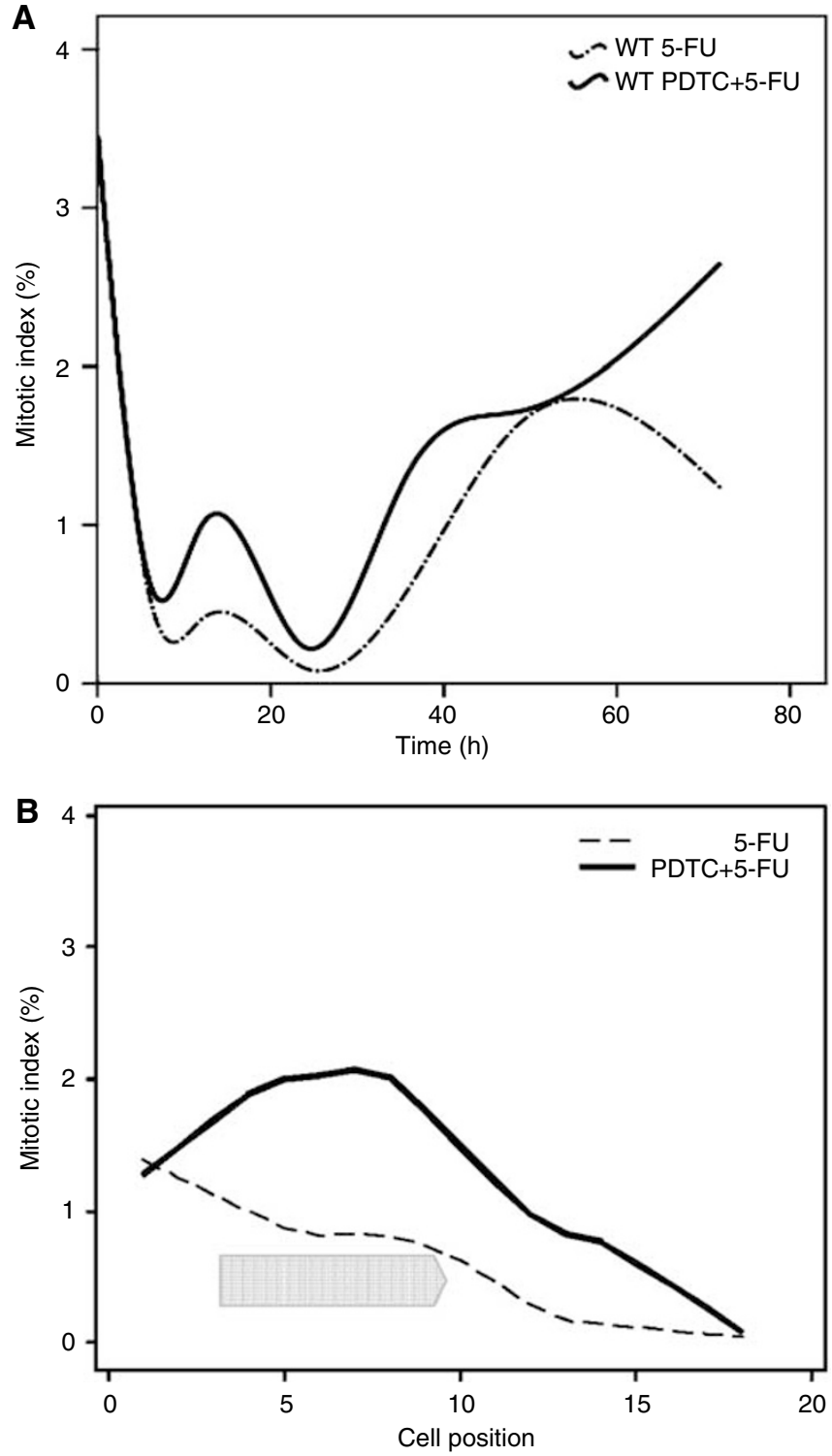

Figure 2 Large intestinal mitosis. (A) Time course of mean mitotic index is displayed for the whole crypt (cell positions I - 18) following $200 \mathrm{mg} \mathrm{kg}^{-1}$ 5 -FU alone $\pm 250 \mathrm{mg} \mathrm{kg}^{-1}$ PDTC in p53 wild-type and p53 null mice. Six animals per group at each time point $(6,12,24,36,48$ and $72 \mathrm{~h}$ ) counting 50 half-crypts per mouse. (B) Mitotic index is displayed for each crypt cell position $72 \mathrm{~h}$ after the administration of treatment in $\mathrm{p} 53$ wild-type mice. Chevron indicates cell positions over which a significant difference was detected between treatments ( $P<0.001$, PC crypts).

via $\mathrm{p} 21^{\mathrm{WAF} 1 / \mathrm{CIP} 1}$ (Chinery et al, 1997). In our model, augmentation of p53-independent apoptosis by PDTC does not result from modulation of $\mathrm{p} 21^{\mathrm{WAF} 1 / \mathrm{CIP} 1}$. Administration of PDTC did not alter the duration of cell cycle arrest as mitotic recovery occurred simultaneously for both groups at $72 \mathrm{~h}$ (data not shown).

It appears that small intestinal crypts can affect programmed cell death by both p53-dependent and -independent pathways following treatment with the antimetabolite 5-FU. We are unable to specify what proportion of late apoptotic events are mediated by p53-dependent and -independent pathways respectfully in the wild-type mouse, although it is clear from their null littermates that appreciable p53-independent activity is possible and that this activity is upregulated by coadministration of PDTC or NAC. As a result, PDTC does not significantly modulate the number of surviving clonogens in the small intestine; mitotic recovery is not 

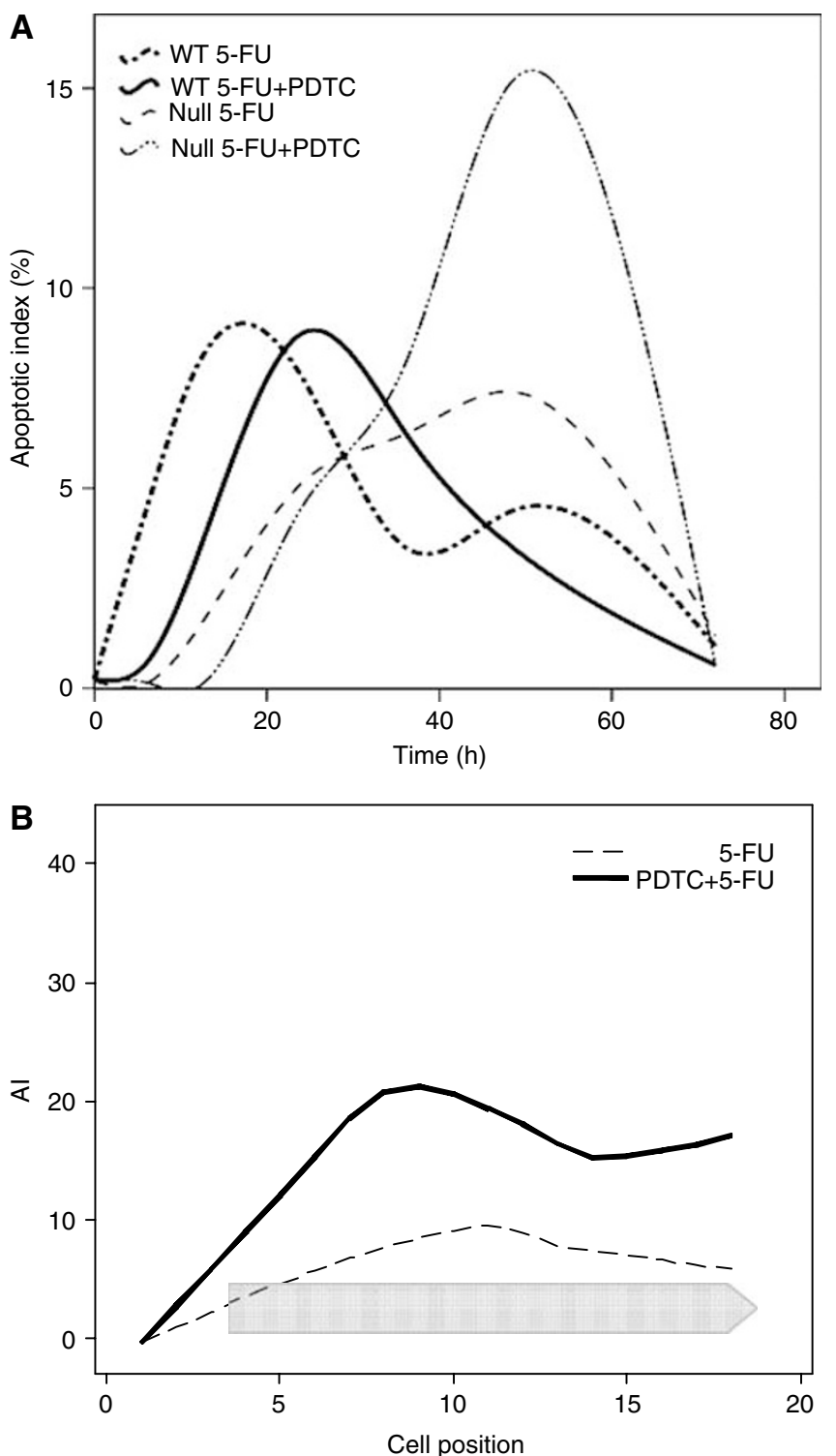

Figure 3 Small intestinal apoptosis. (A) Time course of mean apoptotic index is displayed for the whole crypt (cell positions I-18) following $200 \mathrm{mg} \mathrm{kg}^{-1}$ 5-FU alone $\pm 250 \mathrm{mg} \mathrm{kg}^{-1}$ PDTC in p53 wild-type and p53 null mice. Six animals per group at each time point $(6,12,24,36,48$ and $72 \mathrm{~h}$ ) counting 50 half-crypts per mouse. (B) Apoptotic index is displayed for each crypt cell position $48 \mathrm{~h}$ after the administration of treatment in p53 null mice. Chevron indicates cell positions over which a significant difference was detected between treatments $(P<0.00$ I, PC crypts).

expedited and consequently this agent has no impact upon small intestinal crypt survival (Bach et al, 2000).

\section{Molecular control of intestinal toxicity}

The mechanism by which 5-FU induces apoptosis in the normal intestine involves initial interference of RNA signalling pathways followed by activation of the p53 pathway (Pritchard et al, 1997; Bunz et al, 1999; Longley et al, 2002). Several transcriptional targets of p53 are genes whose products generate ROS (Polyak et al, 1997; Macip et al, 2003). It is hypothesised that these products contribute towards p53-mediated apoptosis. In addition, a set of 5-FU-dependent, p53-inducible genes, continue to be defined. In the context of our study, the most interesting of these is
A

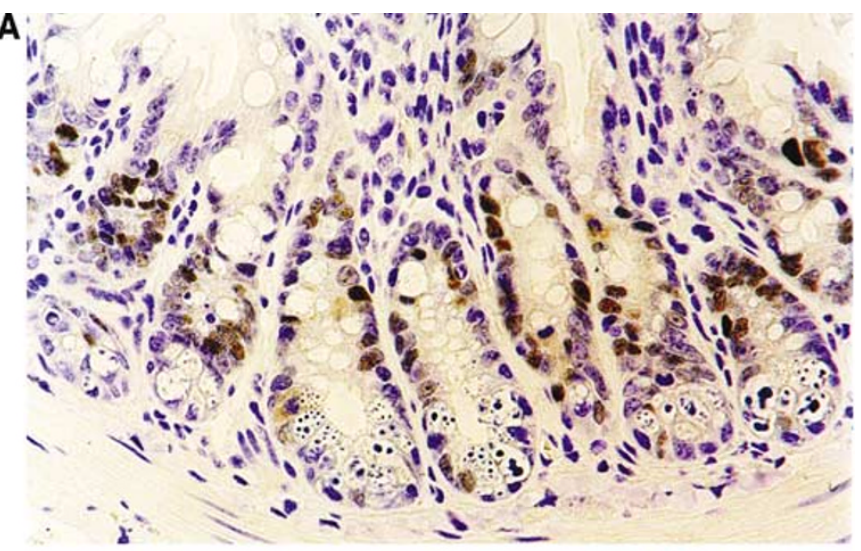

B

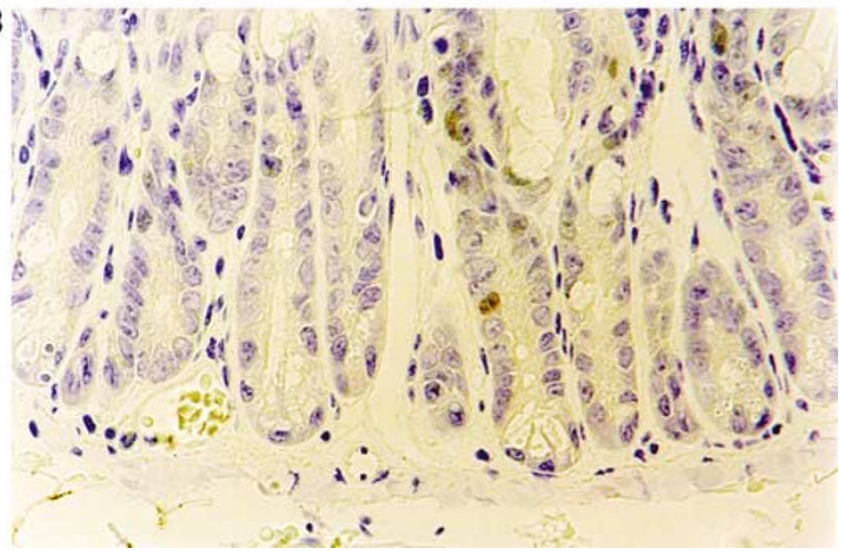

Figure 4 Immunohistochemical sections from $(\mathbf{A})$ p $53+1+(\times 400)$ and (B) p53-1- mouse small intestinal crypts $(\times 500)$ stained for p2I WAF1 $48 \mathrm{~h}$ following $200 \mathrm{mg} \mathrm{kg}^{-1} 5-\mathrm{FU}$ and $250 \mathrm{mg} \mathrm{kg}^{-1}$ PDTC.

a gene coding for mitochondrial ferredoxin reductase (FDXR). Ferredoxin reductase may represent a mechanism by which ROS are generated. Reactive oxygen species cause permeabilisation of the mitochondrial membrane with release of the proapoptotic proteins cytochrome $c$ and apaf-1 (Kroemer and Reed, 2000). Ferredoxin reductase expression following 5-FU exposure in a p53 $+I+$ CRC cell line correlated with increased oxidative stress and apoptosis (Hwang et al, 2001). Increasing levels of FDXR independent of 5-FU therapy did not result in increased apoptosis (Liu and Chen, 2002). Ferredoxin reductase contains a p53responsive element in its promoter region (Liu and Chen, 2002). The effects of 5-FU were abrogated in FDXR knockout clones and pharmacological inhibition of 5-FU activity was achieved by the use of two antioxidant agents, ubiquinol and a mitochondrialtargeted derivative mitoQ (Hwang et al, 2001). MitoQ was shown to prevent the reduced clonogenicity associated with 5-FU treatment in vitro in accordance with our results using PDTC and 5-FU in vivo (Bach et al, 2000). A mechanism therefore exists to explain the observed reduction in p53-driven apoptosis following the addition of PDTC or NAC to 5-FU therapy.

Apoptosis does not feature in the response of $\mathrm{p} 53$ null colonic enterocytes to 5-FU (Figure 1A). Similar effects have been reported in this model following radiation treatment (Merritt et al, 1994) and in a colorectal cancer cell line subject to 5-FU (Bunz et al, 1999). Interestingly, the five most highly transcriptionally activated genes in a CRC cell line following 5-FU exposure all possess putative p53 response elements (Maxwell et al, 2003). It seems likely that the unspecified p53-independent apoptotic mechanism present within small intestinal enterocytes and augmented by PDTC is simply absent from colonocytes. 
In conclusion, it appears that large intestinal crypts affect apoptosis purely by p53-dependent mechanisms, whereas small intestinal crypts are able to initiate both p53-dependent and independent pathways following treatment with 5-FU. Pyrrolidinedithiocarbamate and NAC antagonised p53-dependent but potentiated p53-independent apoptotic activity. Consequently, the proportion of surviving clonogens increased in the large but not in the small intestine and early recovery of normal mitotic activity occurred only in the large bowel. Functional outcome at a tissue level is measured in terms of improved large bowel crypt regeneration 6 days after an enterotoxic schedule of 5-FU (Bach et al, 2000). Despite the fact that PDTC modulates murine large bowel toxicity to 5-FU in isolation, this finding may still be of clinical relevance. We have previously shown that 5-FU is relatively more toxic (by a factor of one log) to large as opposed to small intestinal crypts in our mouse model (Bach et al, 2000). Evidence exists to suggest that this situation may also be replicated in humans (Milles et al, 1962). Pyrrolidinedithiocarbamate or NAC in addition to other agents with similar biochemical properties may therefore reduce the p53-driven apoptotic events that mediate 5FU-related drug-induced toxicity. p53-independent apoptotic pathways that are likely to be recruited therapeutically were not similarly affected. The potential to reduce diarrhoea during multimodality neoadjuvant therapy for rectal cancer should also be examined further.

\section{ACKNOWLEDGEMENTS}

We thank all the members of the Potten laboratory for their valuable input, especially Nicola Cragg, Julie O'Shea, Emma Marshman, Penny Ottewell, Dawn Booth, Caroline Chadwick, Greg Tudor and Cath Booth. SPB was supported by a Christie Hospital Endowment Award.

Supplementary Information accompanies the paper on British Journal of Cancer website (http://www.nature.com/bjc)

\section{REFERENCES}

Alexandre J, Batteux F, Nicco C, Chereau C, Laurent A, Guillevin L, Weill B, Goldwasser F (2006a) Accumulation of hydrogen peroxide is an early and crucial step for paclitaxel-induced cancer cell death both in vitro and in vivo. Int J Cancer 119: $41-48$

Alexandre J, Nicco C, Chereau C, Laurent A, Weill B, Goldwasser F, Batteux F (2006b) Improvement of the therapeutic index of anticancer drugs by the superoxide dismutase mimic mangafodipir. J Natl Cancer Inst 98: $236-244$

Bach SP (2003) Antioxidants as modulators of 5-fluorouracil therapy in colorectal cancer. In Faculty of Medicine, Dentistry, Nursing and Pharmacy, pp 219. University of Manchester

Bach SP, Chinery R, O’Dwyer ST, Potten CS, Coffey RJ, Watson AJ (2000) Pyrrolidinedithiocarbamate increases the therapeutic index of 5-fluorouracil in a mouse model. Gastroenterology 118: 81-89

Bach SP, Williamson SE, Marshman E, Kumar S, O’Dwyer ST, Potten CS, Watson AJ (2001) The antioxidant $n$-acetylcysteine increases 5 -fluorouracil activity against colorectal cancer xenografts in nude mice. J Gastrointest Surg 5: $91-97$

Bruck R, Aeed H, Schey R, Matas Z, Reifen R, Zaiger G, Hochman A, Avni Y (2002) Pyrrolidine dithiocarbamate protects against thioacetamideinduced fulminant hepatic failure in rats. J Hepatol 36: 370-377

Bunz F, Hwang PM, Torrance C, Waldman T, Zhang Y, Dillehay L, Williams J, Lengauer C, Kinzler KW, Vogelstein B (1999) Disruption of p53 in human cancer cells alters the responses to therapeutic agents [see comments]. J Clin Invest 104: 263-269

Burns ER, Beland SS (1984) Effect of biological time on the determination of the $\mathrm{LD}_{50}$ of 5-fluorouracil in mice. Pharmacology 28: 296-300

Buroker TR, O'Connell MJ, Wieand HS, Krook JE, Gerstner JB, Mailliard JA, Schaefer PL, Levitt R, Kardinal CG, Gesme Jr DH (1994) Randomized comparison of two schedules of fluorouracil and leucovorin in the treatment of advanced colorectal cancer. J Clin Oncol 12: 14-20

Chinery R, Brockman JA, Peeler MO, Shyr Y, Beauchamp RD, Coffey RJ (1997) Antioxidants enhance the cytotoxicity of chemotherapeutic agents in colorectal cancer: a p53-independent induction of p21WAF1/CIP1 via C/EBPbeta. Nat Med 3: $1233-1241$

Chwalinski S, Potten CS (1989) Crypt base columnar cells in ileum of BDF1 male mice - their numbers and some features of their proliferation. Am J Anat 186: $397-406$

Donehower LA, Harvey M, Slagle BL, McArthur MJ, Montgomery CA, Jr, Butel JS, Bradley A (1992) Mice deficient for p53 are developmentally normal but susceptible to spontaneous tumours. Nature 356: 215-221

Fawcett H, Mader JS, Robichaud M, Giacomantonio C, Hoskin DW (2005) Contribution of reactive oxygen species and caspase- 3 to apoptosis and attenuated ICAM-1 expression by paclitaxel-treated MDA-MB-435 breast carcinoma cells. Int J Oncol 27: 1717-1726

Huang HL, Fang LW, Lu SP, Chou CK, Luh TY, Lai MZ (2003) DNAdamaging reagents induce apoptosis through reactive oxygen speciesdependent Fas aggregation. Oncogene 22: 8168-8177
Hwang PM, Bunz F, Yu J, Rago C, Chan TA, Murphy MP, Kelso GF, Smith RA, Kinzler KW, Vogelstein B (2001) Ferredoxin reductase affects p53dependent, 5-fluorouracil-induced apoptosis in colorectal cancer cells. Nat Med 7: $1111-1117$

Ijiri K, Potten CS (1983) Response of intestinal cells of differing topographical and hierarchical status to ten cytotoxic drugs and five sources of radiation. Br J Cancer 47: 175-185

Ikeda K, Kajiwara K, Tanabe E, Tokumaru S, Kishida E, Masuzawa Y, Kojo $S$ (1999) Involvement of hydrogen peroxide and hydroxyl radical in chemically induced apoptosis of HL-60 cells. Biochem Pharmacol 57: $1361-1365$

Kang J, Chen J, Zhang D, Da W, Ou Y (2004) Synergistic killing of human leukemia cells by antioxidants and trichostatin A. Cancer Chemother Pharmacol 54: 537-545

Kroemer G, Reed JC (2000) Mitochondrial control of cell death. Nat Med 6: 513- 519

Levine AJ, Momand J, Finlay CA (1991) The p53 tumour suppressor gene. Nature 351: $453-456$

Liu G, Chen X (2002) The ferredoxin reductase gene is regulated by the p53 family and sensitizes cells to oxidative stress-induced apoptosis. Oncogene 21: $7195-7204$

Longley DB, Boyer J, Allen WL, Latif T, Ferguson PR, Maxwell PJ, McDermott U, Lynch M, Harkin DP, Johnston PG (2002) The role of thymidylate synthase induction in modulating p53-regulated gene expression in response to 5-fluorouracil and antifolates. Cancer Res 62: $2644-2649$

Macip S, Igarashi M, Berggren P, Yu J, Lee SW, Aaronson SA (2003) Influence of induced reactive oxygen species in p53-mediated cell fate decisions. Mol Cell Biol 23: 8576-8585

Maxwell PJ, Longley DB, Latif T, Boyer J, Allen W, Lynch M, McDermott U, Harkin DP, Allegra CJ, Johnston PG (2003) Identification of 5 -fluorouracil-inducible target genes using cDNA microarray profiling. Cancer Res 63: $4602-4606$

Menon SG, Sarsour EH, Spitz DR, Higashikubo R, Sturm M, Zhang H, Goswami PC (2003) Redox regulation of the G1 to S phase transition in the mouse embryo fibroblast cell cycle. Cancer Res 63: 2109-2117

Merritt A, Jones LS, Potten C (1996) Apoptosis in murine intestinal crypts. In Techniques in Apoptosis. A User's Guide, Cotter TG and Martin SJ (eds) pp 271-299. Portland Press: London, UK

Merritt AJ, Potten CS, Kemp CJ, Hickman JA, Balmain A, Lane DP, Hall PA (1994) The role of p53 in spontaneous and radiation-induced apoptosis in the gastrointestinal tract of normal and p53-deficient mice. Cancer Res 54: $614-617$

Milles S, Muggia A, Spiro H (1962) Colonic histologic changes induced by 5-FU. Gastroenterology 43: 391 - 399

Nargi JL, Ratan RR, Griffin DE (1999) p53-independent inhibition of proliferation and p21(WAF1/Cip1)-modulated induction of cell death by the antioxidants $N$-acetylcysteine and vitamin E. Neoplasia 1: 544-556 
Polyak K, Xia Y, Zweier JL, Kinzler KW, Vogelstein B (1997) A model for p53-induced apoptosis [see comments]. Nature 389: 300-305

Potten CS, Owen G, Roberts SA (1990) The temporal and spatial changes in cell proliferation within the irradiated crypts of the murine small intestine. Int J Radiat Biol 57: 185-199

Prescott LF, Donovan JW, Jarvie DR, Proudfoot AT (1989) The disposition and kinetics of intravenous $\mathrm{N}$-acetylcysteine in patients with paracetamol overdosage. Eur J Clin Pharmacol 37: 501-506

Pritchard DM, Potten CS, Hickman JA (1998) The relationships between p53-dependent apoptosis, inhibition of proliferation, and 5-fluorouracilinduced histopathology in murine intestinal epithelia. Cancer Res 58: $5453-5465$

Pritchard DM, Watson AJ, Potten CS, Jackman AL, Hickman JA (1997) Inhibition by uridine but not thymidine of p53-dependent intestinal apoptosis initiated by 5-fluorouracil: evidence for the involvement of RNA perturbation. Proc Natl Acad Sci USA 94: 1795- 1799

Rahmani M, Reese E, Dai Y, Bauer C, Payne SG, Dent P, Spiegel S, Grant S (2005) Coadministration of histone deacetylase inhibitors and perifosine synergistically induces apoptosis in human leukemia cells through Akt and ERK1/2 inactivation and the generation of ceramide and reactive oxygen species. Cancer Res 65: $2422-2432$

Ross SD, Kron IL, Gangemi JJ, Shockey KS, Stoler M, Kern JA, Tribble CG, Laubach VE (2000) Attenuation of lung reperfusion injury after transplantation using an inhibitor of nuclear factor-kappa B. Am J Physiol Lung Cell Mol Physiol 279: L528-536

Sablina AA, Budanov AV, Ilyinskaya GV, Agapova LS, Kravchenko JE, Chumakov PM (2005) The antioxidant function of the p53 tumor suppressor. Nat Med 11: 1306-1313

Sekharam M, Trotti A, Cunnick JM, Wu J (1998) Suppression of fibroblast cell cycle progression in G1 phase by $\mathrm{N}$-acetylcysteine. Toxicol Appl Pharmacol 149: $210-216$

Simizu S, Takada M, Umezawa K, Imoto M (1998) Requirement of caspase -3(-like) protease-mediated hydrogen peroxide production for apoptosis induced by various anticancer drugs. J Biol Chem 273: 26900-26907

Tsuchihashi S, Tamaki T, Tanaka M, Kawamura A, Kaizu T, Ikeda A, Kakita A (2003) Pyrrolidine dithiocarbamate provides protection against hypothermic preservation and transplantation injury in the rat liver: the role of heme oxygenase-1. Surgery 133: 556-567 